Int. J. Electrochem. Sci., 13 (2018) 8915 - 8930

\title{
Effect of Plasma Pre-oxidation on the Cu Corrosion Inhibition in 3.5\% NaCl by an Environmentally Friendly Amide
}

\author{
N. Velazquez-Torres ${ }^{1}$, H. Martinez ${ }^{2}$, J. Porcayo-Calderon $^{1,2}$, E. Vazquez-Velez, ${ }^{2}$, \\ O. Florez, B. Campillo ${ }^{3}$, J.G. Gonzalez-Rodriguez ${ }^{*}$, L. Martinez-Gomez $^{2,4}$ \\ ${ }^{1}$ Universidad Autonoma del Estado de Morelos, CIICAp, Av. Universidad 1001, Col. Chamilpa, \\ 62209-Cuernavaca, Mor., Mexico \\ ${ }^{2}$ Universidad Nacional Autonoma de Mexico, Instituto de Ciencias Fisicas, Av. Universidad S/N, Col. \\ Chamilpa, 62209-Cuernavaca, Mor., Mexico. \\ ${ }^{3}$ Universidad Nacional Autonoma de Mexico, Facultad de Quimica, Circuito Universitario, Mexico, \\ D.F., Mexico \\ ${ }^{4}$ Corrosion y Protección, (CyP), Buffon 46, 11590 Mexico D.F., Mexico \\ *E-mail: ggonzalez@uaem.mx
}

doi: $10.20964 / 2018.09 .07$

Received: 26 February 2018 / Accepted: 27 April 2018 / Published: 5 August 2018

The effect of plasma pre-oxidation on the effect of the inhibition performance of N-[2-[(2hydroxyethyl) amino] ethyl]-amide extracted from coffee bagasse for $\mathrm{Cu}$ in $3.5 \% \mathrm{NaCl}$ has been investigated by using electrochemical techniques. Electrochemical impedance spectroscopy, potentiodynamic polarization curves and linear polarization resistance (LPR) measurements were the employed techniques. Results have shown that the corrosion rate of $\mathrm{Cu}$ was decreased and the properties of the passive film formed by the inhibitor were improved. Corrosion protection given by the inhibitor and pre-oxidizing treatment improves as time elapses due to an increase of the surface area covered by the corrosion products layer. This has been explained in terms of a better adherence of the inhibitor-formed film to the metal which by pre-oxidizing.

Keywords: Copper, pre-oxidation, green inhibitor, corrosion.

\section{$\underline{\text { FULL TEXT }}$}

(C) 2018 The Authors. Published by ESG (www.electrochemsci.org). This article is an open access article distributed under the terms and conditions of the Creative Commons Attribution license (http://creativecommons.org/licenses/by/4.0/). 